\title{
Analisis Pengaruh Temperatur Pirolisis terhadap Kualitas Bahan Bakar Minyak dari Limbah Plastik Polipropilena
}

\author{
(Analysis of Pyrolysis Temperature Effect on Fuel-Oil Quality from Polypropilene Plastict \\ Waste)
}

\author{
M Jahiding $^{1 *}$, E Nurfianti ${ }^{1}$, E S Hasan ${ }^{1}$, R S Rizki ${ }^{1}$, Mashuni ${ }^{2}$ \\ 1) Laboratorium Fisika Material dan Energi, FMIPA, Universitas Haluoleo \\ 2) Laboratorium Kimia Analitik, FMIPA, Universitas Haluoleo
}

nfo

Article history:

Received: 15 Juni 2020

Accepted: 27 Juni 2020

Published: 30 Juni 2020

\section{Kata kunci:}

Pirolisis,

Polipropilena,

Efek temperatur,

Analisis fisis,

Bahan bakar minyak

\section{Keywords:}

Pyrolysis,

Polypropylene,

Temperature effect,

Physics analysis,

Fuel oil

\begin{abstract}
Abstrak.
Tujuan dari penelitian ini adalah untuk mengetahui pengaruh temperatur pirolisis terhadap kualitas fuel-oil dari limbah Polipropilena. Metode yang digunakan adalah pirolisis cepat (fast-pirolisis) tanpa menggunakan katalis. Analisis fisis yang dilakukan meliputi: densitas, viskositas, dan nilai kalor. Limbah plastik Polipropilena dipirolisis dengan temperatur $450{ }^{\circ} \mathrm{C}, 500{ }^{\circ} \mathrm{C}$ dan $550{ }^{\circ} \mathrm{C}$. Hasil analisis menunjukkan bahwa semua profil temperatur memenuhi standar bbm konvensional yang menyerupai BBM konvensional jenis bensin. Pada masing-masing temperatur pirolisis 450, 500 dan $550{ }^{\circ} \mathrm{C}$ diperoleh berturut-turut: rendemen $16 ; 64 ; 70 \%$; viskositas 0,$76 ; 0,92 ; 1,12 \mathrm{cP}$, densitas 0,$750 ; 0,764 ; 0.756 \mathrm{gr} / \mathrm{ml}$ dan nilai kalornya $11.388 ; 11.316 ; 11.356 \mathrm{kkal} / \mathrm{kg}$. Berdasarkan analisis yang telah dilakukan bahan bakar minyak hasil pirolisis limbah plastik polipropilena dapat digunakan sebagai pengganti bahan bakar konvensional karena sudah memenuhi standar karakteristik bahan bakar sesuai American Standard and Testing Material (ASTM).
\end{abstract}

\section{Abstract.}

This study aims to determine the effect of pyrolysis temperature on the quality of fuel-oil from Polypropylene. This study aims to determine the effect of pyrolysis temperature on the quality of fuel-oil from Polypropylene waste. The method used is fast pyrolysis without using a catalyst. Physical analysis performed includes: density, viscosity, and heating value. Polypropylene plastic waste is hydrolyzed at a temperature of $450^{\circ} \mathrm{C}, 500^{\circ} \mathrm{C}$ and $550^{\circ} \mathrm{C}$. The analysis shows that all temperature profiles meet conventional fuel standards which resemble conventional types of gasoline. At pyrolysis temperatures of 450,500 and $550{ }^{\circ} \mathrm{C}$ respectively, obtained: yield 16; 64; 70\%; viscosity 0.76; 0.92; $1.12 \mathrm{cP}$, density 0.750; 0.764; $0.756 \mathrm{gr} / \mathrm{ml}$ and the heating value of 11,388; 11,316; 11,356 kcal / kg. Based on the analysis that has been carried out fuel oil from polypropylene plastic waste pyrolysis can be used as a substitute for conventional fuels because it meets the fuel characteristics standards according to the American Standard and Testing Material (ASTM).

*) e-mail: mjahiding2019@gmail.com

\section{PENDAHULUAN}

Kebutuhan dan komsumsi energi dewasa ini semakin meningkat terutama penggunaan Bahan Bakar Minyak (BBM). Peningkatan kebutuhan bahan bakar minyak salah satunya disebabkan oleh perkembangan industri yang berbahan dasar minyak bumi semakin pesat sehingga menyebabkan cadangan minyak bumi dan gas bumi terbatas. Oleh karena itu diperlukan upaya untuk mencari sumber energi alternatif lain sebagai pengganti bahan bakar minyak yang ramah lingkungan dan ekonomis.

Salah upaya yang dilakukan untuk menciptakan energi alternatif adalah dengan mengkonversi limbah plastik jenis polipropilena (PP) menjadi fuel-oil sebagai bahan bakar pengganti bahan bakar fosil. Plastik berasal dari turunan minyak bumi sehingga pada proses penguraiannya dapat dikembalikan menjadi hidrokarbon sebagai bahan dasar energi [1][2]. Proses daur ulang limbah plastik bertujuan untuk 
mengubah polimer rantai panjang hidrokarbon menjadi rantai yang lebih pendek sebagai bahan baku untuk industri kimia atau produksi bahan bakar [3].

Salah satu metode yang dapat menkonversi limbah plastik polipropilena menjadi fuel-oil adalah pirolisis[4]. Thermal cracking (pirolisis) adalah dekomposisi kimia melalui proses pemanasan tanpa oksigen dimana material mentah akan mengalami pemecahan stuktur menjadi fase gas. Teknik seperti ini dapat menghasilkan gas pembakaran yang aman bagi lingkungan. Pada proses pirolisis hidrokarbon rantai panjang dari polimer plastik akan dipecah menjadi lebih pendek, selanjutnya setelah proses pendinginan molekul ini akan berubah fase menjadi cair[5]. Produk utama hasil pirolisis terdiri atas fraksi cair, gas, dan residu padat [6][7].

Polipropilena adalah polimer yang tersusun atas monomermonomer propena, melalui reaksi polimerisasi adisi membentuk polipropilena. Polipropilena memiliki rumus kimia $\left(\mathrm{C}_{3} \mathrm{H}_{6}\right) \mathrm{x}$, titik lebur $\sim 160{ }^{\circ} \mathrm{C}\left(320{ }^{\circ} \mathrm{F}\right)$ dengan densitas $0.855 \mathrm{~g} / \mathrm{cm}^{3}$. Polipropilena adalah polimer non-polar, semiplastik dan termoplastik digunakan untuk berbagai aplikasi seperti pengemasan, tekstil atau bahkan peralatan medis [8] [9] Plastik Polipropilena memiliki struktur hidrokarbon rantai panjang yang dapat dikonversi menjadi bahan bakar minyak. Dalam produk pirolisis terdapat banyak komponen hidrokarbon termasuk paraffin, olefin, napthene dan senyawa aromatis lainnya yang merupakan bahan baku pembuatan plastik [10]. Pemanfaatan limbah plastik polipropilena sebagai bahan baku produksi bahan bakar alternatif dengan metode pirolisis diharapkan dapat menjadi bahan bakar terbarukan yang setara dengan bahan bakar konvensional.

Konversi limbah polipropilena menjadi fuel-oil dilakukan menggunakan metode pirolisis dilakukan pada suhu 450, 500 dan $550{ }^{\circ} \mathrm{C}$. Uji kualitas fuel-oil dihitung dengan beberapa analisis yaitu, densitas, viskositas dan nilai kalor Pada penelitian ini akan dipelajari pengaruh temperatur terhadap produksi dan kualitas fuel-oil yang dihasilkan dari proses pirolisis limbah plastik polipropilena.

\section{BAHAN DAN METODE}

Bahan yang digunakan dalam penelitian ini adalah sampel limbah plastik polipropilena yang telah dikumpulkan dari berbagai tempat pembuangan limbah dari wilayah Kendari, Sulawesi Tenggara. Alat yang digunakan dalam penelitian ini adalah serangkaian perangkat pirolisis, kertas saring (whatman), piknometer, viskometer, dan gelas ukur.

Preparasi sampel meliputi pencucian limbah plastik polipropilena untuk menghilangkan sisa kotoran yang masih tersisa, kemudian dihilangkan kadar airnya dengan penjemuran di bawah sinar matahari selanjutnya dicacah dengan ukuran 3-5 cm.

Proses konversi limbah polipropilena menjadi fuel-oil dilakukan pada temperature 450, 500 dan $550{ }^{\circ} \mathrm{C}$. Pada penelitian ini $1 \mathrm{~kg}$ limbah plastik polipropilena dimasukkan dalam tangki reaktor. Kemudian, reaktor dipanaskan dari suhu kamar hingga $450{ }^{\circ} \mathrm{C}$ menggunakan tingkat pemanasan $15^{\circ} \mathrm{C}$ / mnt. Langkah selanjutnya adalah menghitung waktu yang dibutuhkan untuk mendekomposisikan plastik hingga cairan fuel-oil berhenti menetes. Hal yang sama juga dilakukan untuk temperature 500 dan $550{ }^{\circ} \mathrm{C}$. Bahan baku limbah plastik diubah menjadi uap dan terkondensasi menjadi minyak cair setelah melewati pipa kondensor dan dikumpulkan dalam wadah. Suhu ruang kondensor dijaga di bawah $10{ }^{\circ} \mathrm{C}$ untuk mencapai kondensasi maksimum uap. Bahan baku yang tidak terbakar (char) dikumpulkan dari ruang pemanas pada akhir setiap percobaan setelah memungkinkan sistem menjadi dingin pada suhu kamar. Pada akhirnya dari setiap percobaan, keseimbangan massa produk pirolisis adalah didirikan melalui penimbangan minyak cair, jumlah lilin / arang dan persentase sisa berat hingga $100 \%$ adalah semuanya diasumsikan sebagai gas.

Densitas fuel-oil dianalisis menggunakan alat piknometer $25 \mathrm{ml}$, kemudian dihitung dengan Persamaan. (1) dan pengukuran sesuai dengan standar ISO 4787 [11][12]. Untuk meminimalkan kesalahan pengukuran, semua pengukuran dilakukan tiga kali untuk setiap sampel dan hasilnya diratarata.

$\rho=\frac{m}{V p}(\mathrm{~g} / \mathrm{mL})$

dimana:

$\mathrm{m}$ : massa (piknometer+sampel)-massa piknometer kosong. Vp: Volume piknometer $(25 \mathrm{ml})$.

Viskositas fuel-oil ditentukan dengan membandingkan viskositas fuel-oil dan viskositas cairan pembanding berupa air menggunakan viskometer ostwald yang melibatkan masingmasing variabel densitas fuel-oil dan densitas air, kemudian dihitung dengan persamaan (2) berikut: [11]

$\frac{\eta_{1}}{\eta_{2}}=\frac{\rho_{1} t_{1}}{\rho_{2} t_{2}}$

dimana:

$\eta_{1}$ : Viskositas fuel-oil (cP)

$\eta_{2}$ : Viskositas air (cP)

$\rho_{1}$ : Densitas fuel-oil $(\mathrm{g} / \mathrm{ml})$

$\rho_{2}$ : Densitas air $(\mathrm{g} / \mathrm{ml})$

$t_{1}$ : Waktu alir fuel-oil (s)

$t_{2}$ : Waktu alir air (s)

Nilai kalor dianalisis dengan melibatkan variabel densitas, spesific gravity dan API (American Petroleum Institute) gravity. Spesific gravity merupakan perbandingan antara densitas fuel-oil dengan densitas air, sedangkan nilai API gravity dihitung menggunakan persamaan berikut[11][13]

${ }^{\circ} \mathrm{API}=141,5 \div \mathrm{SG}-131,5$

$\mathrm{NK}=\frac{2,2046226}{3,9673727} \times(18,650+40 \times(\mathrm{G}-10) \mathrm{kkal} / \mathrm{kg}$.

\section{HASIL DAN PEMBAHASAN}

\section{Pengaruh Suhu Terhadap Yield Fuel-oil dan waktu Pirolisis Limbah Plastik Polipropilena}

Pada penelitian ini sampel yang digunakan adalah limbah plastik polipropilena. Limbah polipropilena sebanyak $1 \mathrm{~kg}$ dipirolisis pada temperatur 450,500 dan $550^{\circ} \mathrm{C}$. Temperature tersebut telah melebihi titik leleh dari plastik polipropilena sehingga menyebabkan plastik tersebut meleleh dan kemudian berubah fase menjadi gas. Pada saat proses pirolisis berlangsung, rantai panjang hidrokarbon akan terpotong menjadi lebih pendek. Selanjutnya pendinginan dilakukan pada gas tersebut sehingga akan mengalami kondensasi dan membentuk cairan. Cairan inilah yang kemudian ditampung dalam gelas erlemenyer.

Peningkatan temperatur pirolisis mempengaruhi yield produk pirolisis yang dihasilkan, pada suhu 450, 500 dan 550 

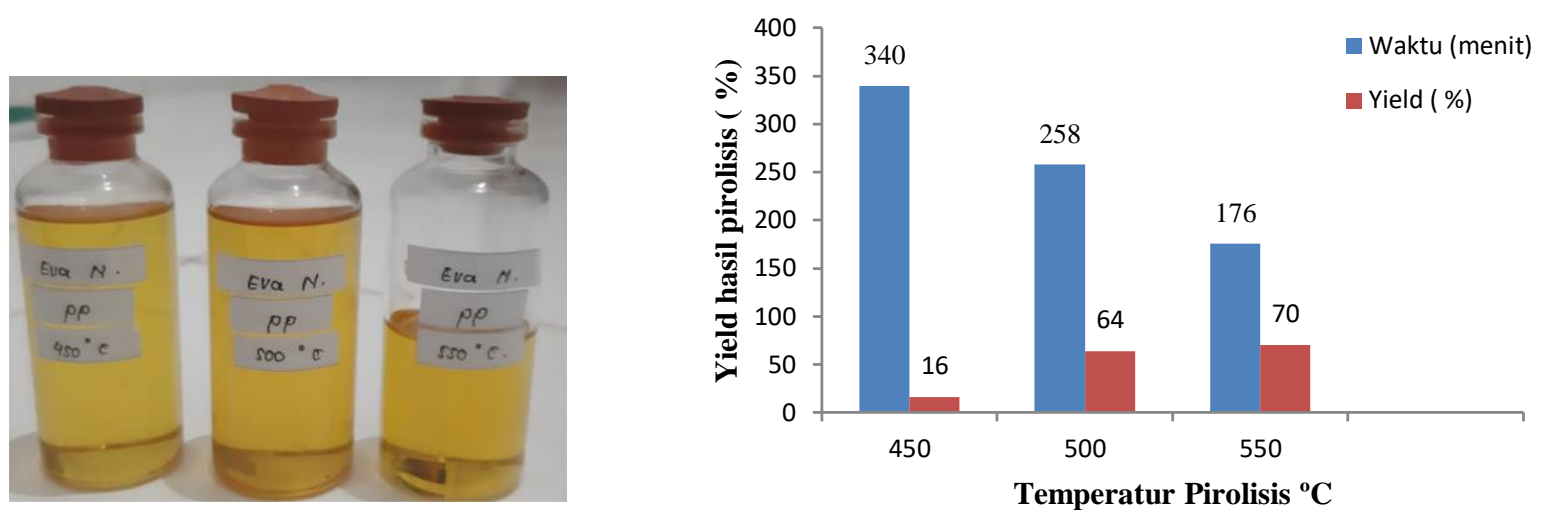

Gambar 1. Fuel-oil hasil pirolisis limbah plastik polipropilena dan grafik efek temperature pirolisis terhadap volume dan waktu pirolisis

${ }^{\circ} \mathrm{C}$ berturut- turut adalah 16, 64 dan $70 \%$. Menurut Wicaksono [14] dengan bertambah tingginya suhu pemanasan maka zatzat yang terkandung dalam plastik akan terurai dengan sempurna. Hal ini disebabkan berdasarkan persamaan Arhenius semakin tinggi suhu maka nilai konstanta dekomposisi termal akan semakin besar yang mengkibatkan laju pirolisis semakin meningkat, sehingga uap hidrokarbon lebih cepat terkondensasi menjadi cairan hidrokarbon [15]. Hal inilah yang menyebabkan waktu pirolisis pada temperatur $550^{\circ} \mathrm{C}$ lebih singkat dibanding pada temperatur $450^{\circ} \mathrm{C}$ dan $500^{\circ} \mathrm{C}$.

Pada Gambar 1 terlihat bahwa peningkatan temperature berbanding lurus dengan volume fuel-oil yang dihasilkan. Hal ini disebabkan oleh banyaknya ikatan rantai karbon yang terputus akibat peningkatan temperature. Selain itu, pada suhu tinggi rantai karbon akan lebih muda terengkah dibandingkan pada temperature rendah [16]. Volume fuel-oil pada temperatur $450^{\circ} \mathrm{C}$ jauh lebih sedikit dibandingkan pada temperatur $500^{\circ} \mathrm{C}$ dan $550^{\circ} \mathrm{C}$ yang meningkat secara signifikan. Hal yang sama juga diungkapkan Ekky Wahyudi [17] bahwa proses perengkahan pada suhu yang lebih rendah menghasilkan produk wax yang tertinggal didalam reaktor yang terdiri dari paraffin dan char yang terkarbonisasi.

Namun pada temperatur $550^{\circ} \mathrm{C}$, meski telah melewati proses penyaringan ketika didiamkan diruang suhu kamar sebagian fuel-oil hasil pirolisis tersebut akan terbentuk koloid, Sehingga apabila dipanaskan koloid tersebut akan menjadi cair kembali. Hal ini terjadi karena ketika limbah plastik dipirolisis diatas titik leburnya dalam artian energi yang diterima limbah plastik lebih besar atau sama dengan titik leburnya menyebabkan terjadinya peleburan pada plastik sehingga terbentuk wax. Selain itu, diatas temperatur $500^{\circ} \mathrm{C}$ terjadi proses dekomposisi produk lebih lanjut menjadi gas sehingga fuel-oil yang dihasilkan akan mulai menurun [18].

\section{Pengaruh temperatur pirolisis terhadap Densitas Fuel-oil}

Massa jenis atau yang biasa disebut densitas merupakan suatu indikator banyaknya zat-zat pengotor hasil reaksi. Densitas adalah salah satu parameter penting dalam menentukan kualitas bahan bakar. Jika massa suatu bahan bakar melebihi standar batasnya, maka akan meningkatkan keausan mesin dan menyebabkan kerusakan mesin [19]. Pada penelitian ini pengukuran densitas menggunakan piknometer dengan volume $10 \mathrm{ml}$ pada suhu $30^{\circ} \mathrm{C}$. Hasil analisis densitas fuel-oil dari piro-katalitik limbah plastik polipropilena ditunjukkan pada Gambar 2.

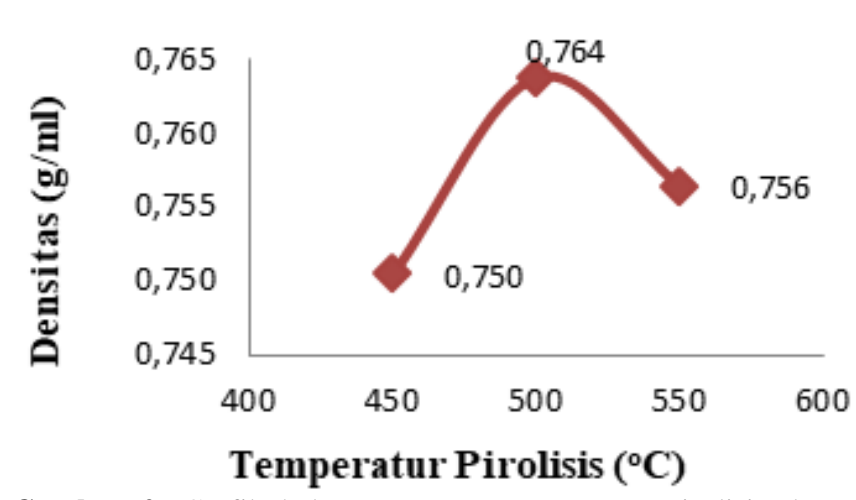

Gambar 2. Grafik hubungan antara temperatur pirolisis dengan densitas

Berdasarkan Gambar 2, densitas fuel-oil yang diperoleh pada penelitian ini berada pada rentang bahan bakar jenis bensin 88 yaitu $0,715 \mathrm{~g} / \mathrm{ml}-0,780 \mathrm{~g} / \mathrm{ml}$ [20][21]. Nilai densitas bahan bakar terlalu tinggi akan meningkatkan keausan mesin dan menyebabkan kerusakan pada mesin. Berdasarkan penelitian yang telah dilakukan, maka hasil terbaik dari pirolisis limbah plastik polipropilena yaitu pada suhu $450^{\circ} \mathrm{C}$ dengan nilai densitas terendah dibandingkan pada suhu $500^{\circ} \mathrm{C}$ dan $550{ }^{\circ} \mathrm{C}$ yaitu $0,750 \mathrm{gr} / \mathrm{ml}$. Nilai densitas tersebut telah memenuhi Standard Range Density bahan bakar premium[22].

\section{Pengaruh temperatur pirolisis terhadap Densitas Fuel-oil}

Viskositas merupakan salah satu parameter penting pada suatu bahan bakar. Nilai viskositas suatu bahan bakar bergantung pada kandungan fraksi ringan dan temperatur disekitarnya. Suatu bahan bakar terlalu encer, maka akan sulit terbakar dan menyebabkan kebocoran pipa injeksi [19]. Nilai viskositas yang tinggi dapat menyebabkan pemompaan cairan dari tangki ke ruang bahan bakar mesin menjadi berat. Hal ini dapat mengakibatkan pembakaran kurang sempurna dan menimbulkan endapan pada nosel. Pengukuran viskositas pada penelitian ini menggunkan viskometer ostwaldpada temperatur $30^{\circ} \mathrm{C}$. Hasil analisis viskositas Fuel-oil hasil pirolisis limbah plastik polipropilena ditunjukkan pada Gambar 3.

Pada Gambar 3 tersebut menunjukkan hasil analisis viskositas yang dihasilkan pada temperature $450^{\circ} \mathrm{C}, 500^{\circ} \mathrm{C}$ dan $550^{\circ} \mathrm{C}$ yaitu $0,756 \mathrm{cP}, 0,922 \mathrm{cP}$ dan $1,120 \mathrm{cP}$. Menurut Weldan Fauzi Syahputro [23] nilai viskositas berbanding lurus dengan nilai densitasnya. Pada penelitian ini nilai viskositas tertinggi 
diperoleh pada temperatur $550{ }^{\circ} \mathrm{C}$. Hal ini terjadi karena fueloil hasil pirolisis pada temperatur $550{ }^{\circ} \mathrm{C}$ mengandung wax sehingga ketika dilakukan pengukuran viskositas waktu aliran fuel-oil melambat akibat wax tersebut, sehingga nilai viskositas atau kekentalannya tinggi. Dapat disimpulkan bahwa pada penelitian ini, hasil terbaik dari pirolisis limbah plastik polipropilena yaitu pada temperatur $450{ }^{\circ} \mathrm{C}$ yang memiliki nilai densitas dan viskositas sebesar $0,7504 \mathrm{~kg} / \mathrm{L}$ dan $0,756 \mathrm{cP}$.

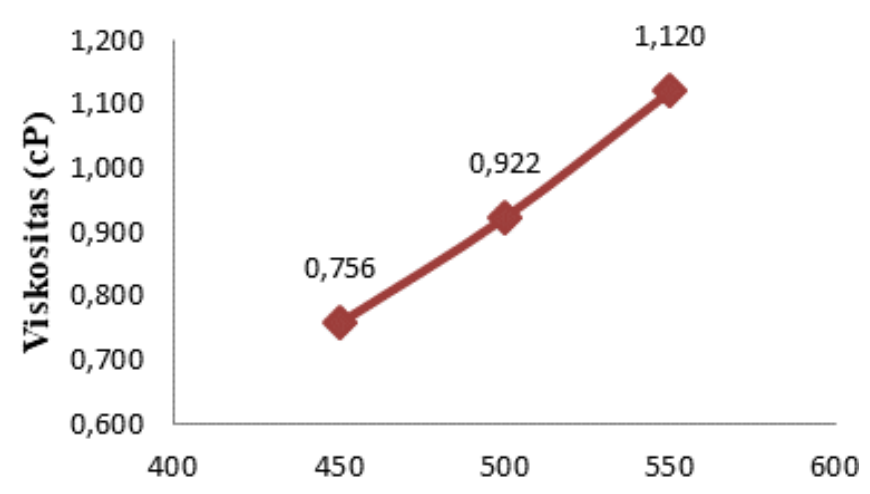

Temperatur Pirolisis $\left({ }^{\circ} \mathrm{C}\right)$

Gambar 3. Grafik hubungan antara temperatur pirolisis dengan viskositas

Berdasarkan penelitian Rahmat Jaya Eka Syaputra, dkk [24] diperoleh nilai densitas fuel-oil pada temperatur $450{ }^{\circ} \mathrm{C}$ adalah $0,754 \mathrm{~g} / \mathrm{ml}$ dan viskositas $0,723 \mathrm{cP}$. Hasil yang diperoleh masuk dalam range standar bensin komersial pertamina sesuai keputusan direktur jendral minyak dan gas bumi No. $3674 \mathrm{~K} / 24 / \mathrm{DJM} / 2006$ memiliki densitas $\left(60{ }^{\circ} \mathrm{F}\right)$ $0,715-0,780 \mathrm{gr} / \mathrm{ml}$.

\section{Pengaruh temperatur piro-katalitik terhadap nilai kalor Fuel-oil}

Nilai kalor merupakan suatu angka yang menyatakan jumlah panas yang dihasilkan dari proses pembakaran suatu bahan bakar dengan udara. Penentuan nilai kalor dapat dilakukan dengan cara pengukuran menggunakan instrumen calorimeter bomb [25] dan cara perhitungan [26]. Pada penelitian ini, penentuan nilai kalor dilakukan dengan cara perhitungan yang melibatkan variabel densitas, API Gravity dan Specific Gravity. Persamaan yang digunakan dalam menghitung nilai kalor dapat dilihat pada persamaan (4). Nilai kalor dari bahan bakar minyak umumnya berkisar antara $10.160 \mathrm{kcal} / \mathrm{kg}-11.000$ $\mathrm{kkal} / \mathrm{kg}$ [27]. Hasil analisis nilai kalor BBM plastik dari hasil pirolisis limbah plastik polipropena ditunjukkan pada Gambar 4.

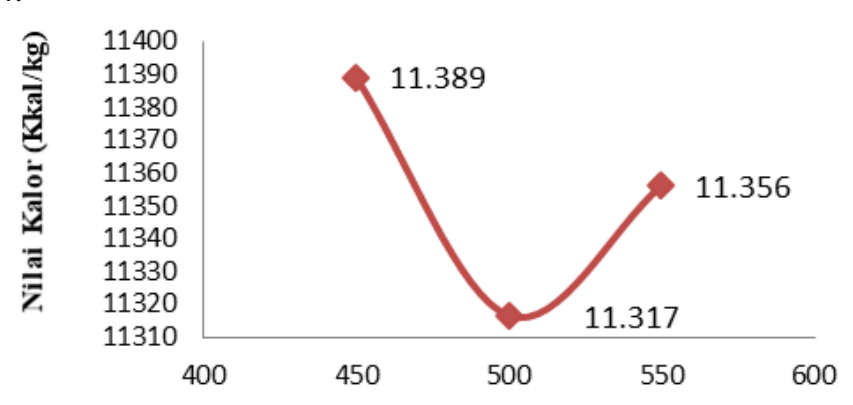

Temperatur Pirolisis $\left({ }^{\circ} \mathrm{C}\right)$

Gambar 4. Hubungan temperature pirolisis dengan nilai kalor
Gambar 4 menunjukkan nilai kalor yang dihasilkan pada temperatur $450^{\circ} \mathrm{C}, 500^{\circ} \mathrm{C}$ dan $550^{\circ} \mathrm{Cyaitu} 11.389 \mathrm{kkal} / \mathrm{kg}$ $(47,647 \mathrm{MJ} / \mathrm{kg}), 11.317 \mathrm{kkal} / \mathrm{kg}(47,346 \mathrm{MJ} / \mathrm{kg})$ dan 11.356 $\mathrm{kkal} / \mathrm{kg}(47,514 \mathrm{MJ} / \mathrm{kg})$. Ketiga fuel-oil yang diperoleh memenuhi standar nilai BBM konvensional yang dipasarkan didalam negri (dept. ESDM RI, 2008) karena nilai kalor ketiga fuel-oil tersebut diatas $10.000 \mathrm{kkal} / \mathrm{kg}(41,879 \mathrm{MJ} / \mathrm{kg})$. Adapun nilai kalor yang diperoleh mendekati nilai kalor bensin premium yaitu $11.245 \mathrm{kkal} / \mathrm{kg}$ [27]. Jadi, ketiga fuel-oil merupakan jenis bensin premium.

Nilai kalor berbanding terbalik dengan densitas. Jika nilai densitasnya rendah maka nilai kalor yang dihasilkan tinggi. [26].

\section{KESIMPULAN}

Berdasarkan hasil analisis dan bahasan diatas, dapat disimpulkan fuel-oil produk pirolisis plastik polipropilena lebih mendekati bahan bakar jenis bensin (premium) baik dilihat dari tampilan visual, densitas, viskositas dan nilai kalornya. Hal yang sama pula diungkapkan pada penelitian Muhammad Rijani [28], Rahmat Jaya Eka Syaputra [24], Ekky Wahyudi [17] dan Ismi Qurratul'uyun (2017). Namun hasil yang diperoleh belum murni bensin, Fuel-oil tersebut juga mengandung bahan bakar jenis kerosin-diesel, maka dari itu perlu dilakukan destilasi bertingkat untuk memisahkan fraksi bahan bakar minyak yang masih bercampur, seperti fraksi bensin, kerosin maupun solar. Dengan demikian limbah plastik polipropilena dapat diproduksi menjadi BBM jenis bensin sebagai sumber bahan bakar alternatif sekaligus dapat mengatasi pencemaran yang disebabkan oleh limbah plastik.

\section{DAFTAR PUSTAKA}

[1] T. Anggono and A. Rahmadani, "Pirolisis Sampah Plastik Untuk Mendapatkan Asap Cair dan Penentuan Komponen Kimia Penyusunnya Serta Uji Kemampuannya Sebagai Bahan Bakar Cair," vol. 3, no. 2, pp. 164-173, 2009.

[2] A. Brems, J. Baeyens, And R. Dewil, "Recycling and Recovery of Post-Consumer Plastic," Therm. Sci., vol. 16, no. 3, pp. 669-685, 2012, doi: 10.2298/TSCI120111121B.

[3] T. Schubert, M. Lehner, T. Karner, W. Hofer, and A. Lechleitner, "Influence of reaction pressure on copyrolysis of LDPE and a heavy petroleum fraction," Fuel Process. Technol., vol. 193, no. April, pp. 204-211, 2019, doi: 10.1016/j.fuproc.2019.05.016.

[4] K. Ding, Z. Zhong, B. Zhang, J. Wang, A. Min, and R. Ruan, "Catalytic pyrolysis of waste tire to produce valuable aromatic hydrocarbons: An analytical PyGC/MS study," J. Anal. Appl. Pyrolysis, vol. 122, pp. 5563, 2016, doi: 10.1016/j.jaap.2016.10.023.

[5] Nasrun, E. Kurniawan, and I. Sari, "Pengolahan Limbah Kantong Plastik Jenis Kresek Menjadi Bahan Bakar Menggunakan Proses Pirolisis," J. Energi Elektr., vol. 4, no. 1, pp. 1-5, 2017, doi: 10.29103/jee.v4i1.11.

[6] A. G. Buekens and H. Huang, "Catalytic plastics cracking for recovery of gasoline-range hydrocarbons from municipal plastic wastes," Resour. Conserv. Recycl., vol. 23, no. 3, pp. 163-181, 1998, doi: 10.1016/S0921-3449(98)00025-1.

[7] Mashuni, L. O. Kadidae, M. Jahiding, M. A. Dermawan, and F. H. Hamid, "Pemanfaatan Kulit Buah Kakao 
sebagai Antibakteri Escherichia coli dan Staphylococcus aureus," BioWallacea J. Penelit. Biol. (Journal Biol. Res., vol. 6, no. 2, p. 1017, 2019, doi: 10.33772/biowallacea.v6i2.9009.

[8] P. Pedrosa, J. M. Chappé, C. Fonseca, A. V. Machado, J. M. Nóbrega, and F. Vaz, "Plasma surface modification of polycarbonate and poly(propylene) substrates for biomedical electrodes," Plasma Process. Polym., vol. 7, no. 8, pp. 676-686, 2010, doi: 10.1002/ppap.200900176.

[9] M. F. Maitz, "Applications of synthetic polymers in clinical medicine," Biosurface and Biotribology, vol. 1, no. 3, pp. 161-176, 2015, doi: 10.1016/j.bsbt.2015.08. 002.

[10] J. Scheirs, Overview of Commercial Pyrolysis Processes for Waste Plastics. 2006.

[11] I. M. A. Sutrisna Wijaya, I. G. K. Arya Arthawan, and A. Novita Sari, "Potensi nira kelapa sebagai bahan baku bioetanol," J. Bumi Lestari, vol. 12, no. 1, pp. 85-92, 2012.

[12] M. Gülüm and A. Bilgin, "Density, flash point and heating value variations of corn oil biodiesel-diesel fuel blends," Fuel Process. Technol., vol. 134, pp. 456-464, 2015, doi: 10.1016/j.fuproc.2015.02.026.

[13] S. M. Awadh and H. S. Al-Mimar, "Statistical Analysis of the Relations between API, Specific Gravity and Sulfur Content in the Universal Crude Oil," Int. J. Sci. Res., vol. 4, no. September, pp. 2319-7064, 2013, [Online]. Available: www.ijsr.net.

[14] M. A. Wicaksono and A. Arijanto, "Pengolahan Sampah Plastik Jenis Pet(Polyethilene Perepthalathe) Menggunakan Metode Pirolisis Menjadi Bahan Bakar Alternatif," J. Tek. Mesin, vol. 5, no. 1, pp. 9-15, 2017.

[15] S. Gitakarma, L. Krisnawati, W. Sutaya, K. U. Ariawan, and A. Adiarta, "Pengembangan Teknik Pengolahan Sampah Plastik Menjadi Minyak di TPST Desa Anturan, Buleleng," Semin. Nas. Vokasi dan Teknol., vol. 22, pp. 353-360, 2016.

[16] A. O. Priyatna, Zultiniar, and E. Saputra, "Perengkahan Katalitik Limbah Plastik Jenis Polypropylene ( $\mathrm{Pp}$ ) Menjadi Bahan Bakar Minyak," Jom Fteknik, vol. 2, no. 2, pp. 1-5, 2015.

[17] E. Wahyudi and E. Saputra, "Pengolahan Sampah Plastik Polipropilena ( PP ) Menjadi Bahan Bakar Minyak dengan Metode Perengkahan Katalitik Menggunakan Katalis Sintetis Processing of Polypropylene ( PP ) Plastic Waste Into Oil Fuel by Catalytic Cracking Method Using Synthetic Catalyst," J. Rekayasa Kim. dan
Lingkung., vol. 11, no. 1, pp. 17-23, 2016.

[18] W. W. Mandala, M. S. Cahyono, S. Ma'arif, H. Sukarjo, and W. Wardoyo, "Pengaruh Suhu terhadap Rendemen dan Nilai Kalor Minyak Hasil Pirolisis Sampah Plastik," J. Mek. dan Sist. Termal, vol. 1, no. 2, pp. 49-52, 2016.

[19] E. Setiawati and F. Edwar, "178872-ID-teknologipengolahan-biodiesel-dari-miny jelantah.pdf," J. Ris. Ind., vol. 6, no. 2, pp. 1-11, 2012.

[20] E. Melyna and I. Zahrina, "Perengkahan Sampah Plastik ( HDPE , PP , PS ) Menjadi Precursor Bahan Bakar dengan Variasi Perbandingan Bahan Baku / Katalis," 2011.

[21] N. Garg, S. Mohan, A. Pal, and R. S. Mishra, "Fuel Adulteration, Problem and Mitigation Strategies: A Review," in International Conference of Advance Research and Innovation (ICARI-2015), 2015, pp. 340 344.

[22] K. Ding et al., "Catalytic microwave-assisted pyrolysis of plastic waste over $\mathrm{NiO}$ and $\mathrm{HY}$ for gasoline-range hydrocarbons production," Energy Convers. Manag., vol. 196, no. April, pp. 1316-1325, 2019, doi: 10.1016/j.enconman.2019.07.001.

[23] W. F. SYAHPUTRO, “ANALISA LAJU PEMANASAN TERHADAP HASIL PRODUK PIROLISIS SAMPAH PLASTIK JENIS PP UNTUK BAHAN BAKAR ALTERNATIF," Simki-Techsain, vol. 02, no. 07, 2018.

[24] R. J. eka saputra tri utami K. D. N. A. F. R. W. Astuti, "Pemanfaatan Limbah Pecahan Genteng sebagai Katalis dalam Reaksi Pirolisis Plastik Polipropilena Menjadi Bahan Bakar Alternatif," J. Rekayasa Kim. dan Lingkung., vol. 10, no. 3, pp. 127-134, 2015.

[25] A. Demirbas, "Pyrolysis of municipal plastic wastes for recovery of gasoline-range hydrocarbons," J. Anal. Appl. Pyrolysis, vol. 72, no. 1, pp. 97-102, 2004, doi: 10.1016/j.jaap.2004.03.001.

[26] I. Wiratmaja, "Pengujian Karakteristik Fisika Biogasoline Sebagai Bahan Bakar Alternatif Pengganti Bensin Murni," J. Energi Dan Manufaktur, vol. 4, no. 2, pp. 145-154, 2010.

[27] D. Mustofa and F. Zainuri, "Pirolisis Sampah Plastik Hingga Suhu 900oC Sebagai Upaya Menghasilkan Bahan Bakar Ramah Lingkungan," 2014.

[28] M. Rijani and C. Rangkuti, "Konversi Plastik Polipropilena Menjadi Bahan Bakar Minyak," in Seminar Nasional Cendekianwan, 2015, pp. 229-236. 